\title{
Characterization of methane hydrate host sediments using synchrotron-computed microtomography (CMT)
}

\author{
Keith W. Jones ${ }^{\text {a }}$, Huan Feng ${ }^{b}$, Stanmire Tomov ${ }^{\mathrm{c}}$, William J. Winters ${ }^{\mathrm{d}}$, \\ Maša Prodanović ${ }^{\mathrm{e}}$, Devinder Mahajan ${ }^{\mathrm{f}, *}$ \\ a Laboratory for Earth and Environmental Sciences, Environmental Sciences Department, \\ Brookhaven National Laboratory, Upton, NY 11973-5000 USA \\ ${ }^{\mathrm{b}}$ Department of Earth and Environmental Studies, Montclair State University, Upper Montclair, NJ 07043 USA \\ c Information Technology Division, Brookhaven National Laboratory, Upton, NY 11973-5000 USA \\ ${ }^{\mathrm{d}}$ U.S. Geological Survey, Woods Hole Science Center, Woods Hole, MA 02543 USA \\ ' Department of Applied Mathematics and Statistics, Stony Brook University, Stony Brook, NY 11794-3600 USA \\ ${ }^{\mathrm{f}}$ Energy Sciences and Technology Department, Brookhaven National Laboratory, Upton, NY 11973-5000 USA, \\ Department of Materials Science and Engineering, Stony Brook University, Stony Brook, NY 11794-2275 USA
}

Received 4 December 2005; accepted 4 March 2006

\begin{abstract}
The hydrate-sediment interaction is an important aspect of gas hydrate studies that needs further examination. We describe here the applicability of the computed microtomography (CMT) technique that utilizes an intense X-ray synchrotron source to characterize sediment samples, two at various depths from the Blake Ridge area (a well-known hydrate-prone region) and one from Georges Bank, that once contained methane trapped as hydrates. Detailed results of the tomographic analysis performed on the deepest sample $(667 \mathrm{~m})$ from Blake Ridge are presented as 2-D and 3-D images which show several mineral constituents, the internal grain/pore microstructure, and, following segmentation into pore and grain space, a visualization of the connecting pathways through the pore-space of the sediment. Various parameters obtained from the analysis of the CMT data are presented for all three sediment samples. The micro-scale porosity values showed decreasing trend with increasing depth for all three samples that is consistent with the previously reported bulk porosity data. The 3-D morphology, pore-space pathways, porosity, and permeability values are also reported for all three samples. The application of CMT is now being expanded to the laboratoryformed samples of hydrate in sediments as well as field samples of methane hydrate bearing sediments.
\end{abstract}

Published by Elsevier B.V.

Keywords: Methane hydrate; Guest-host complexes; Host sediments; Computed microtomography (CMT)

\footnotetext{
* Corresponding author. Tel.: +1 631344 4985; fax: +1 631344 7905 .

E-mail address: dmahajan@bnl.gov (D. Mahajan).
}

\section{Introduction}

There is a renewed worldwide interest in the study of natural gas hydrate because of its potential impact on world energy resources (Collett, 2001), control on seafloor stability (Paull et al., 2000a), significance as a drilling hazard (Collett et al., 2000), and probable 
impact on climate as a reservoir of a major greenhouse gas (Kennett et al., 2003). Gas hydrate is a crystalline solid composed of water and natural gas that is stable at the high pressure and low temperature conditions found along many continental margins and also beneath and within permafrost in Arctic regions (Sloan, 1998). Gas hydrate samples have been recovered at 19 or more areas worldwide and are believed to occur at about 77 locations (Kvenvolden and Lorenson, 2001).

Gas hydrates are part of highly dynamic systems in which fluid movement, gas composition, host sediment type, pore water salinity, pore pressure, and temperature contribute to its formation, growth, stability, and dissociation. Controversy exists over whether natural gas hydrate: (a) is free floating in the sediment matrix, (b) contacts, but does not cement, existing sediment grains, or (c) actually cements and stiffens the bulk sediment (Sakai, 1999). Seismic surveys, one of the most economical and efficient methods to prospect for hydrates over a large area, can provide knowledge of the location of large hydrate concentrations because hydrate within sediment pores can have a profound influence on seismic properties. Consequently, the ability to image a sample at the grain scale and to map the porosity and permeability is of great interest in studying hydrates. Grain scale properties are also of interest for broader studies to understand diagenesis in sedimentary systems undergoing compression and fluid expulsion.

The CMT technique provides a nondestructive method for measuring various sediment parameters at the grain scale. The high-resolution CMT data can be used to generate model parameters that predict behavior of the methane hydrate bearing sediments at meso- and macro-scales. This is analogous to the analysis of sandstone properties from high-resolution tomographic measurements (Coles et al., 1998). In previously reported studies of tomographic imaging, Mikami et al. (2000); Uchida et al. (2000); and Tomutsa et al. (2002) used industrial-type scanners with conventional tube-type Xray sources. Typical voxel sizes for these measurements were $0.6 \mathrm{~mm} \times 0.6 \mathrm{~mm} \times 1.0 \mathrm{~mm}\left(0.36 \mathrm{~mm}^{3}\right)($ Uchida et al., 2000) and $0.2 \mathrm{~mm} \times 0.2 \mathrm{~mm} \times 1.0 \mathrm{~mm}\left(0.04 \mathrm{~mm}^{3}\right)$ (Tomutsa et al., 2002). In their experiment, Uchida et al. (2000) identified six types of natural gas hydrates related to size and location within the sediment matrix. Although some massive hydrate was thicker than $100 \mathrm{~mm}$, porespace hydrate was sometimes as small as $0.001 \mathrm{~mm}$. Therefore, examination of pore-scale hydrate requires higher resolution than is possible with typical industrial scanners. It is inferred that there is a need to make measurements at several different size scales using different available analytical techniques.
In this study, we examined the morphology and related properties of three sediment samples. The CMT data collection and reconstruction were performed at the National Synchrotron Light Source (NSLS) at Brookhaven National Laboratory (BNL) (Fig. 1). The high X-ray intensity of the synchrotron X-ray source makes it possible to work with much smaller voxel sizes, $3 \mu \mathrm{m} \times 3 \mu \mathrm{m} \times 3 \mu \mathrm{m}$, than were used in previous $\mathrm{X}$-ray imaging experiments. The smaller voxel size makes it possible to investigate the microstructure of sediments on a size scale that is not easily feasible with industrial tube-type scanners. We note that there is a tradeoff between pixel size and sample size since the digital camera at the NSLS has a fixed number of pixels. Pixel size must be increased for larger diameter samples. In this study, the size of the camera's charge-coupled device (CCD) was 1317 pixels $\times 1035$ pixels. Hence, the maximum field-of-view at a resolution of $3 \mu \mathrm{m} /$ pixel was $3.951 \mathrm{~mm} \times 3.105 \mathrm{~mm}$. The work reported here used a pixel size of $6.8 \mu \mathrm{m} \times 6.8 \mu \mathrm{m}$ which is much smaller than pixel sizes of previous studies. The corresponding voxel volume was $3.14 \times 10^{2} \mu \mathrm{m}^{3}$. Therefore, use of the synchrotron X-ray source can produce better-resolution images of gas hydrates and has a greater potential to answer important questions, such as the pore filling versus cementation issue, than can industrial scanners. It is also noteworthy that CMT measurements can be performed on samples stored in cryostats where in situ hydratepreserving pressure and temperature conditions can be maintained. The extension of this study would be to form methane hydrate in host sediments using simulated subsurface conditions and image gas hydrate, liquid (water), gas, and solid (sediment) components of the specimen. The test samples could be either produced in the laboratory or sediments containing natural preserved hydrate.

We present here results from the CMT study that focused on determining the applicability of the CMT technique to characterize sediment samples, two at various depths from the Blake Ridge area (a well-known hydrate-prone region) and one from Georges Bank, that once contained methane hydrates, referred to as "host sediments." The 3-D morphology, pore-space pathways, porosity, and permeability values extracted from the measured CMT data are also presented.

\section{Experimental procedures}

\subsection{Geological setting and sample locations}

The samples tested in this study were recovered from the Blake Ridge and Georges Bank. Blake Ridge, located about $280 \mathrm{~km}$ off the South Carolina coast, has 
$A / D \&$

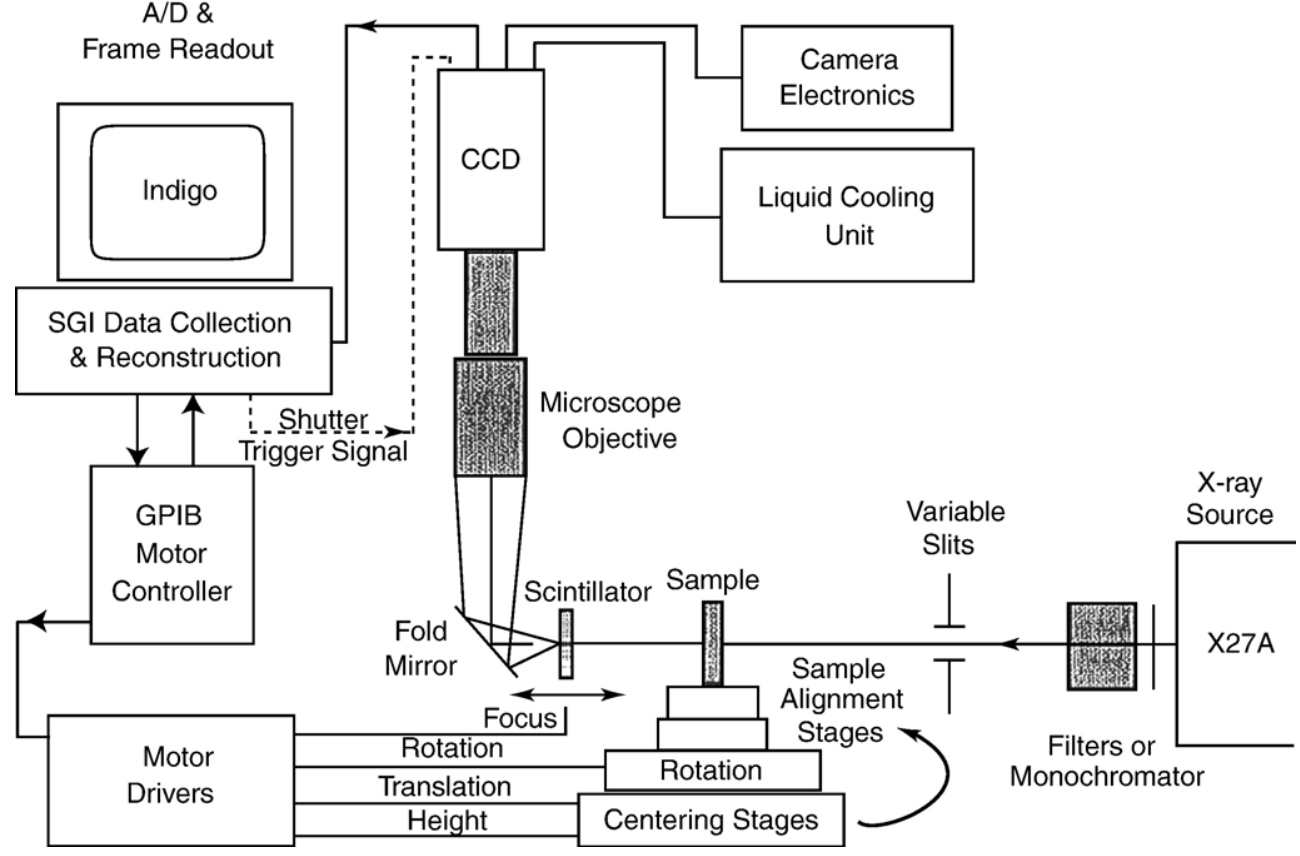

Fig. 1. Schematic diagram of major components of the computed microtomography apparatus used at the National Synchrotron Light Source, Brookhaven National Laboratory. The computed microtomography data was processed to yield images of test sediment specimens.

been extensively studied by the U.S. Geological Survey (USGS) (Dillon et al., 2001) and the Ocean Drilling Program (ODP) (for example, Paull et al., 2000b). It represents a passive-margin sediment drift deposit formed by contour currents, and consists of hemipelagic mud deposited at relatively rapid rates (Heezen et al., 1966). Two samples from depths of $50 \mathrm{~m}$ and $667 \mathrm{~m}$ respectively below the mud line were obtained from this site. Georges Bank is an elongated basin within the continental shelf, approximately $240 \mathrm{~km}$ long by $120 \mathrm{~km}$ wide, situated about $120 \mathrm{~km}$ off the New England coast. Sediments are typically coarser-grained silty sands, sands, and gravel in water depths that range from $40 \mathrm{~m}$ to $60 \mathrm{~m}$ (Emery and Uchupi, 1965). However, our sample number GB-0.2 (Table 1) originating from the flank of the bank at $0.2 / \mathrm{m}$ depth was finergrained. All three samples were devoid of methane hydrates.

\subsection{Sample preservation and particle-size analysis}

After their recovery, samples were preserved in a refrigerator within a closed container and used as received. The grain size distributions of the sediments were determined using a laser light-scattering technique (Freud et al., 1990, 1993; ISO Standard 13320-1) by Microtrac Inc., Largo, Florida.

\subsection{CMT sample preparation}

For the CMT experiments, a small amount of wet, intact sediment $(\sim 0.5 \mathrm{~g})$ was placed in a polyethylene tube with an inside diameter of $4.71 \mathrm{~mm}$ and a wall thickness of $0.81 \mathrm{~mm}$. Care was exercised to maintain the spatial integrity of the sediment sample as the tube was filled. The results obtained should be representative of in situ sediment structures.

\subsection{CMT apparatus}

The sediment microstructure was studied using the CMT beam line X-27A apparatus at the NSLS (Fig. 1). Synchrotron radiation provides a very high intensity Xray beam with a continuous energy distribution; its properties are well adapted to studying materials such as sediments, sand, limestone, and rock samples (Jones et al., 2003). The data collection procedure is as follows. Typically, an area beam is used to illuminate the sample and surrounding air. The X-rays are detected with an yttrium aluminum garnet (YAG) scintillator that is viewed by a CCD camera. The complete tomographic data set consists of 2000 exposures taken as the sample is rotated through $180^{\circ}$ in $0.09^{\circ}$ increments. The tomographic volume is then computed using a Fast-Fourier Transformation (FFT) method (Dowd et al., 1999). Data 
Table 1

Samples locations and properties ${ }^{\mathrm{a}}$

\begin{tabular}{|c|c|c|c|}
\hline Sample ID & GB- 0.2 & BLR-50 & BLR-667 \\
\hline Cruise & OC178 & ODP leg 164 & ODP leg 164 \\
\hline Latitude & $41^{\circ} 51.5^{\prime} \mathrm{N}$ & $31^{\circ} 48.210^{\prime} \mathrm{N}$ & $31^{\circ} 48.210^{\prime} \mathrm{N}$ \\
\hline Longitude & $68^{\circ} 18.1^{\prime} \mathrm{W}$ & $75^{\circ} 31.343^{\prime} \mathrm{W}$ & $75^{\circ} 31.343^{\prime} \mathrm{W}$ \\
\hline Hole/core/section & 27-GC2 & $995 \mathrm{~A}-7 \mathrm{H}-1$ & $995 \mathrm{~A}-80 \mathrm{X}-1$ \\
\hline Water depth (m) & 222 & 2278.5 & 2278.5 \\
\hline Subbottom depth (m) & 0.2 & 49.57 & 666.85 \\
\hline $\begin{array}{l}\text { Water content } \\
\text { ( } M \text { water/ } \\
M \text { solids) }(\%)\end{array}$ & 141 & 87.9 & 39.3 \\
\hline $\begin{array}{l}\text { Maximum past stress, } \\
\mathrm{kPa}\end{array}$ & 4.2 & 205 & 2730 \\
\hline Bulk porosity (\%) & 79.2 & 70.0 & 51.0 \\
\hline
\end{tabular}

${ }^{\mathrm{a}}$ From Winters et al. (2000a).

acquisition and processing both require about 2 to $3 \mathrm{~h}$ each. Voxel sizes employed in this experiment were $3.14 \times 10^{2} \mu \mathrm{m}^{3}$. The energy of the X-ray beam was $18 \mathrm{keV}$. It is also noteworthy that CMT measurements can be performed on samples contained in cryostats where the sample pressure and temperature can be controlled to simulate conditions found in sediments that contain methane hydrates. The tomographic data presented were corrected for ring artifacts and overexposed pixels.

\subsection{CMT image analysis procedure}

The 3DMA-rock software developed by Lindquist et al. (http://www.ams.sunysb.edu/ lindquis/3dma/ $3 \mathrm{dma}$ rock $/ 3 \mathrm{dma}$ rock.html) was utilized for analysis and interpretation of the collected CMT data. The starting point in the CMT analysis is the production of a histogram of the 3-D tomographic image attenuation coefficients. Only the actual sediment sample voxels were used in the process and that voxels outside the sample volume were discarded. Segmentation of the image into pore- and rock-space was performed with an indicator-kriging based algorithm (Oh and Lindquist, 1999) that is part of the 3DMA-rock suite. In order to perform the segmentation and transform the image into a binary form, we chose a maximum attenuation coefficient for the pore-space (threshold $T_{0}$ ) and minimum attenuation coefficient for the rock-space (threshold $T_{1}$ ) from the histogram. The indicator kriging algorithm assigns any voxel with an attenuation coefficient value below $T_{0}$ as phase 0 (pore-space), and any voxel with coefficient value above $T_{1}$ as phase 1 (rock-space). The classification of the intermediate region voxels is then based on a maximum likelihood estimation utilizing a two-point covariance function based on the raw image to guarantee smoothness of the surface between the phases. Such analysis led to the reconstruction of the sediment microstructure for all three sediment samples.

\section{Results and discussion}

Measurements of stress history and geotechnical properties of the sediments are listed in Table 1. The listed porosity values are of interest because the voids in the host sediments are likely to influence methane hydrate formation (Clennell et al., 1999; Wright et al., 1999). It has been found from field studies that hydrates preferentially occupy the void space of some layers and not the adjacent strata of different grain or pore size (Winters et al., 1999 and references therein). The measured porosity data (Table 1) refer to total sample porosity (macro-scale) and is related to the water content of the sediment. The porosity values measured by the CMT technique (Table 2) are those of the three host sediment samples (GB-0.2. BLR-50, and BLR-667) from depths of $0.2 \mathrm{~m}, 50 \mathrm{~m}$, and $667 \mathrm{~m}$ respectively at grain size (micro porosity) and are essentially independent of the water content.

The grain size distributions of the three sediment samples analyzed by Microtrac are shown in Fig. 2. The data show slight variability between the two Blake Ridge samples obtained at different subbottom depths. The sand, silt, and clay amounts are $1.5 \%, 51.2 \%$, and $47.2 \%$ for BLR-50 and $0.2 \%, 52.3 \%$, and $47.5 \%$ for BLR-667 (Winters et al., 2000b). As expected, these distributions differ markedly from the Georges Bank sample (GB-0.2). A large fraction of the sediments was smaller than the voxel size used in the CMT measurement. Given that this produced a partial volume effect that can affect extraction of porosity and other parameters from the CMT data, the calculated porosities

Table 2

Results from CMT measurements

\begin{tabular}{|c|c|c|c|}
\hline Sample ID & GB- 0.2 & BLR-50 & BLR-667 \\
\hline Bulk porosity (\%) & $79.2^{\mathrm{a}}$ & $70.0^{\mathrm{a}}$ & $51.0^{\mathrm{a}}$ \\
\hline CMT porosity $(\%)$ & 83.0 & 68.6 & 55.8 \\
\hline $\begin{array}{l}\text { CMT specific surface area, } \mathrm{m}^{-1} \\
\text { (based on a 2-D correlation } \\
\text { function analysis) }\end{array}$ & 26466 & 28177 & 17062 \\
\hline $\begin{array}{l}\text { CMT specific surface area, } \mathrm{m}^{-1} \\
\text { (based on calculation of surface } \\
\text { area following segmentation) }\end{array}$ & 3176 & 3744 & 2538 \\
\hline $\begin{array}{l}\text { CMT permeability, Darcy (based } \\
\text { on calculation of surface area } \\
\text { following segmentation) }\end{array}$ & 368.4 & 79.0 & 48.1 \\
\hline CMT tortuosity & 1.79 & 1.81 & 1.89 \\
\hline
\end{tabular}




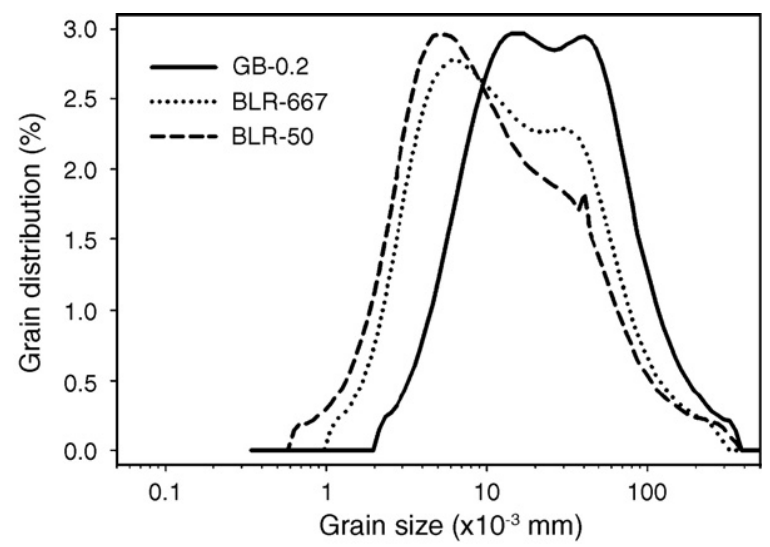

Fig. 2. Grain size distributions of samples GB-0.2, BLR-50, and BLR667. The data were collected by Microtrac, Inc. using a laser-scattering technique.

agree quite well with values determined from water content data (Table 1). This is, however, not surprising since the volume fraction of the larger particles scales roughly as the cube of the dimension. Thus, despite the fact that in these sediments the number of small particles is greater than the number of large particles, their volume fraction is less than the fraction occupied by the larger particles measured in this experiment. Although it

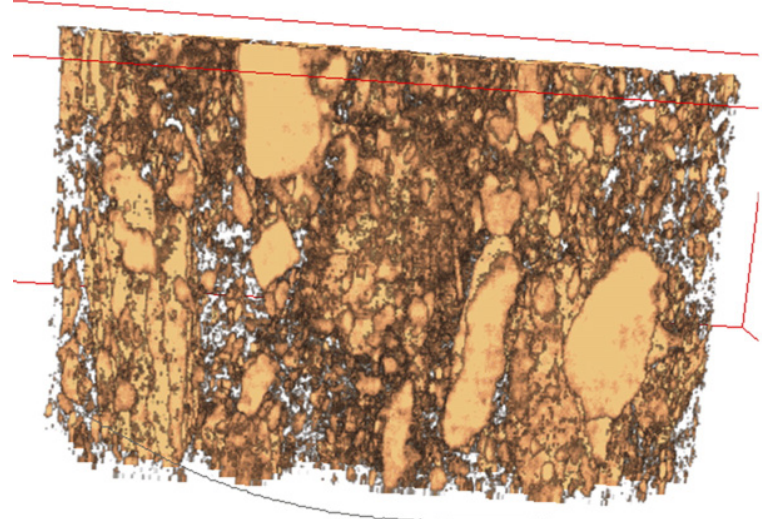

$\begin{array}{lllllllll}0.0029 & 0.0032 & 0.0034 & 0.0037 & 0.0039 & 0.0041 & 0.0044 & 0.0047 & 0.0049\end{array}$

Fig. 3. Computed microtomography volume visualization of the attenuation coefficients measured for sample BLR-667 produced this three-dimensional image in which pore-space is transparent. The volume dimension is 1107 pixels $\times 1007$ pixels $\times 199$ pixels. A portion of the bounding box for the data is shown by the red lines. The color scale at the bottom of the figure gives an indication of the range of attenuation coefficients of the solid voxels displayed. The number of particles as a function of the attenuation is shown by the curve just above the color scale. The 3-D microstructure of the sediments is clearly revealed.

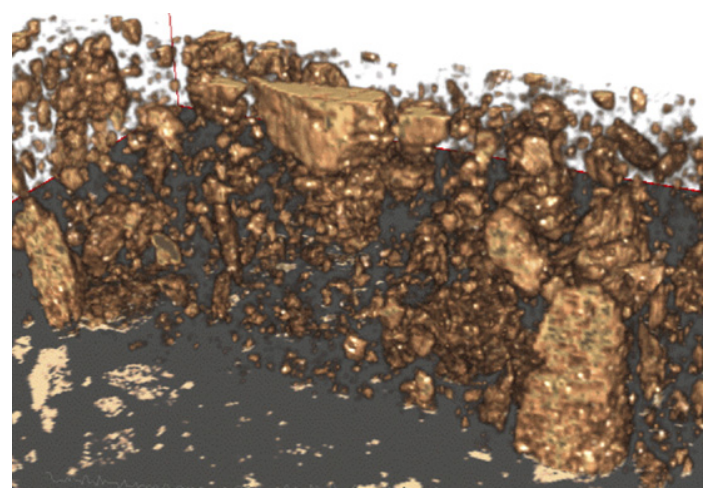

Fig. 4. A magnified view of a portion of the volume displayed in Fig. 3 The volume dimension is 199 pixels $\times 300$ pixels $\times 22$ pixels. The two Figs. ( 3 and 4 ) emphasize the heterogeneity of the sediment particle distributions.

is not emphasized in the logarithmic display used in Fig. 2 to delineate fine structure at small scales, there is also a rather flat continuum of particles with sizes up to several hundred micrometers, especially in the Georges Bank sample. The differences in grain sizes between the Blake Ridge and Georges Bank locations show that CMT measurements yield useful results in more than one size range.

CMT measurements on hydrate-containing samples could also include water, ice, and gases as well. The processed CMT data yield a 3-D matrix related to the Xray attenuation coefficients of individual voxels and

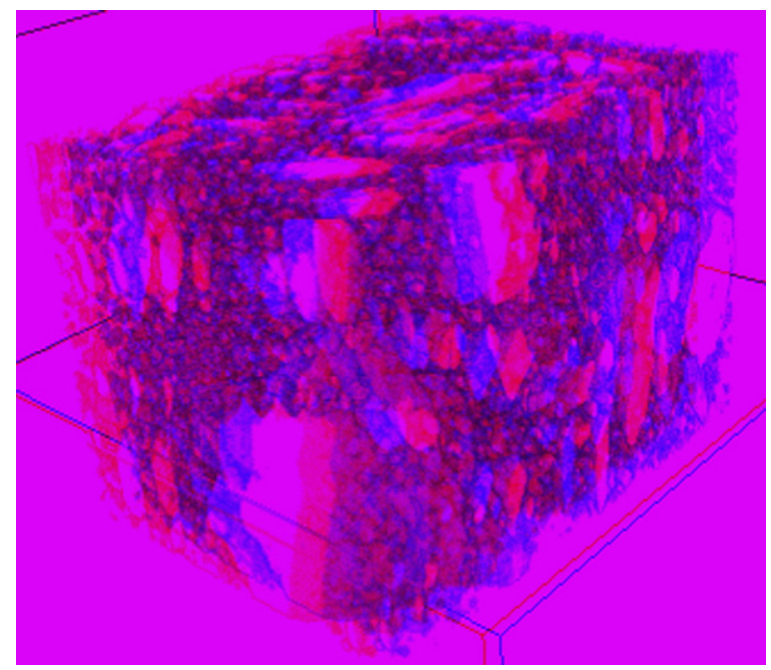

Fig. 5. A stereo representation of the volume data can be obtained by viewing the figure with red-blue stereo glasses. This type of display should be helpful in making comparisons of hydrate bearing and nonhydrate bearing sediments. The volume shown has the same dimensions as the one shown in Fig. 3. 
allow differentiation between solids, liquids, and other pore-space contents.

Data collected for the deepest specimen BLR-667 are displayed in a 3-D view in Fig. 3. The volume dimension is 1107 pixels $\times 1007$ pixels $\times 199$ pixels. The relative attenuation coefficients are shown in the color scale at the bottom of the figure. To allow comparison between various minerals, the displayed attenuation units are voxel $^{-1}$. The space occupied by the pores and particles with smaller values of attenuation have been rendered transparent. This view of the tomographic data demonstrates the ability of the CMT technique to produce highresolution images of the grain-pore geometry. Fig. 4 depicts an expanded view of a smaller segment of the Fig. 3 data with a volume of 199 pixels $\times 300$ pixels $\times 22$ pixels. Notice the relationship between the smaller sediment particles, the pore-space, and larger particles. The 3-D nature of the data can also be exploited through the use of stereo viewing techniques for example using red-blue eye glasses for stereoscopic images (Fig. 5). These, and other, visualization methods will be invaluable in assessing the mechanisms and importance of cementation processes in methane hydrate bearing sediments.

The sediment microstructure was interpreted using the t3DMA-rock software Based on the 3-D tomographic image attenuation coefficients, the complex nature of the BR-667 sediment sample is evident in its histogram (Fig. 6). There are clearly visible peaks corresponding to void (pore and water) space, $\mathrm{SiO}_{2}$, and clay minerals. The results of this segmentation for sample BLR-667 are shown in Fig. 7. The upper image is a section through the tomographic data. The atten-

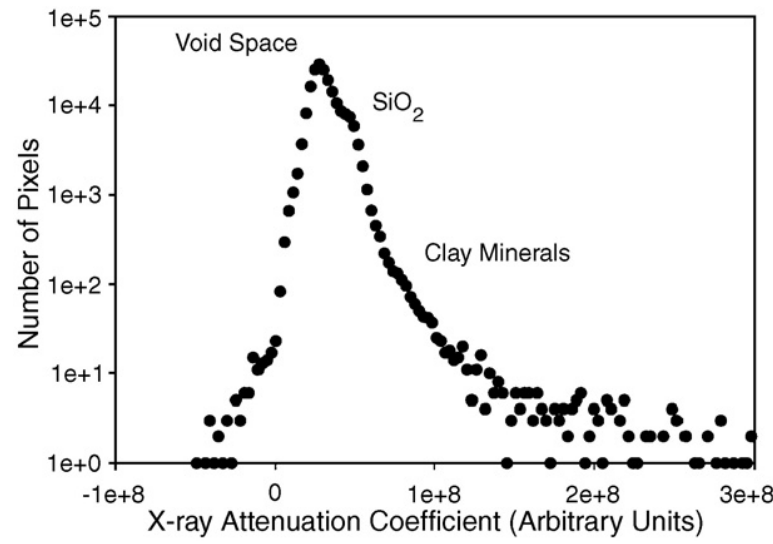

Fig. 6. A histogram of the experimental data obtained for sample BLR667 (see Figs. 3-5) is shown as a function of the X-ray attenuation coefficients. The attenuation values are used to identify void space, $\mathrm{SiO}_{2}$, and clay mineral compounds and to serve as the basis for segmentation of the data into void and solid voxels.
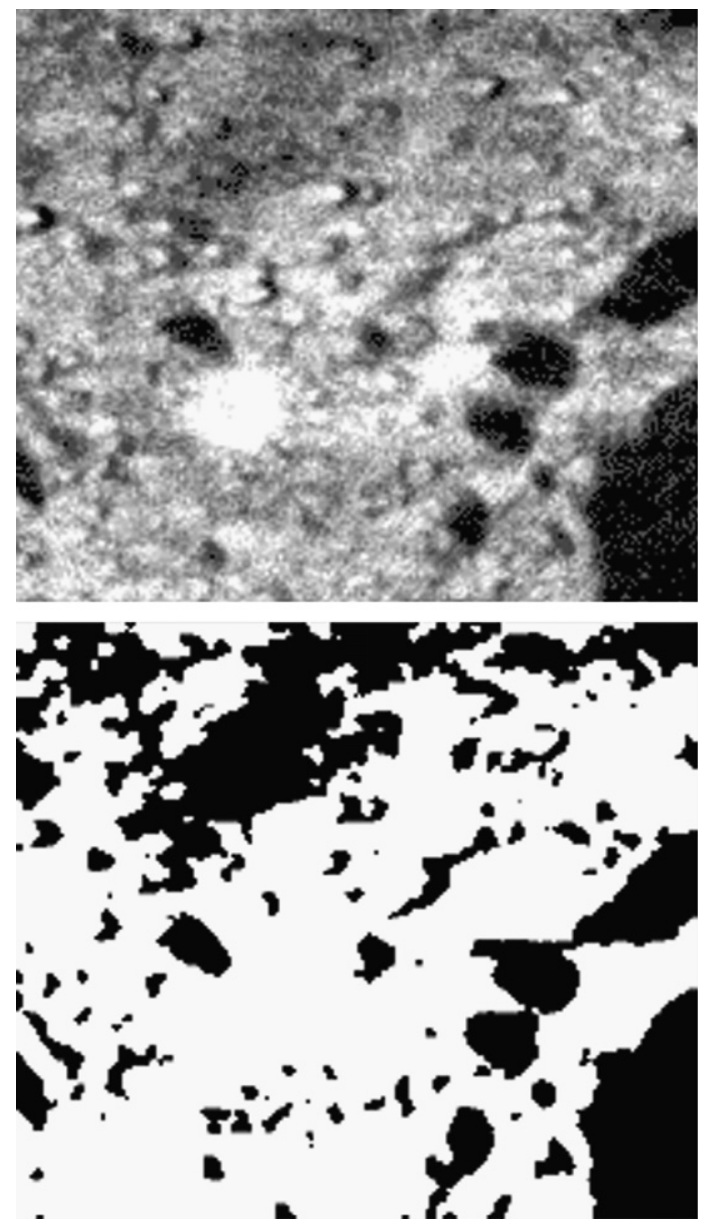

Fig. 7. Binary image of sample BLR-667 (dimensions: $200 \times 200$ pixels) showing solid space in black and pore-space in white for a linear slice through the sediment. The separation is based on the data shown in Fig. 6.

uation coefficients are given in a gray scale representation. The lower image shows a binary representation of the data. Here, black represents rock voxels and white represents pore voxels.

The porosity of the material is calculated after the conversion into a binary form. This is a trivial process since it is given by the ratio of the pore-space voxels to the sum of the pore- and rock-space voxels. The calculated porosity in Fig. 7 is that of the grain sized host sediments and is, therefore, appropriately referred to as porosity at the micrometer scale. The micro porosity values (error margin $\pm 10 \%$ ) for the three samples measured by CMT are summarized in Table 2 along with the bulk porosity values that were previously determined by the gravimetric method (Winters et al., 2000a). A comparison of the bulk and the micro porosity data in Table 2 show that the two sets of values are in agreement 
within an error margin of up to $10 \%$, an error margin placed on the CMT calculations. The general agreement of the two sets supports the validity of the 3DMA-rock software for extracting porosity data from the measured attenuation coefficients.

The 2-D covariance functions can be used to estimate porosity, specific surface area, mean grain size, and permeability of the test sediment (Fig. 8). The $x$-axis variant lag represents a vector $(\boldsymbol{u})$, and the graph shows the probability that two-points separated by the vector are in the same phase (solid or pore). The mathematical treatment of this covariance function has been discussed previously (Berryman and Blair, 1986). The fraction of rock voxels is given by the value of the covariance function at zero lag or by the square root of the value at very large lags. The value of the porosity is given by: (1$S(0)$ ) where $S(0)$ is the value of the covariance function at zero lag. Values are consistent with the voxel count method, as would be expected. The specific surface area is given by

$S^{\prime}(0)=-S / 4$

where $S(0)$ is the slope of the covariance function evaluated at zero lag and $s$ is the specific surface area. The specific surface area can also be found by calculating the area of the rock surfaces using the triangulated interface between rock and pore voxels using the marching cubes algorithm (Lorensen and Cline, 1987) provided by 3DMA-rock and comparing the results with the size of the volume considered. Results for the two approaches

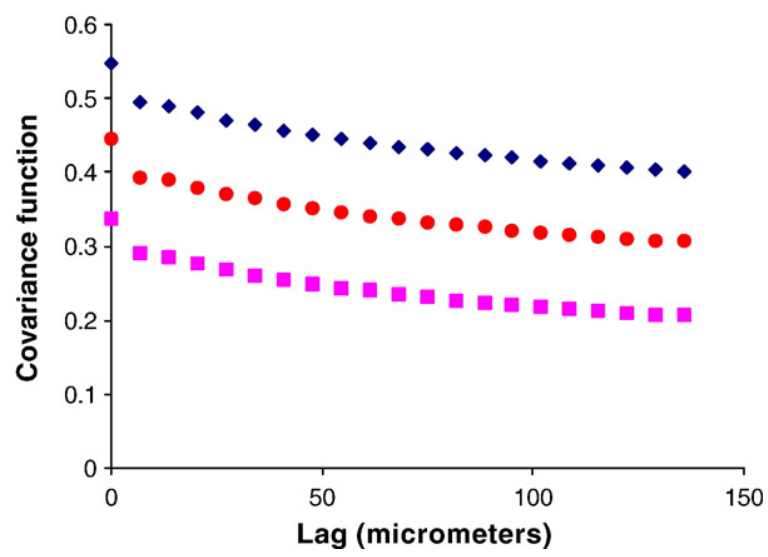

Fig. 8. Two-dimensional covariance function for sample BLR-667. The covariance function is plotted as a function of the lag function. The covariance function is averaged over the rows in a particular slice as a function of the separation between pixels and then plotted for all slices in the tomographic volume. The dashed curves delineate the region one standard deviation above and below the average coefficient of variance.

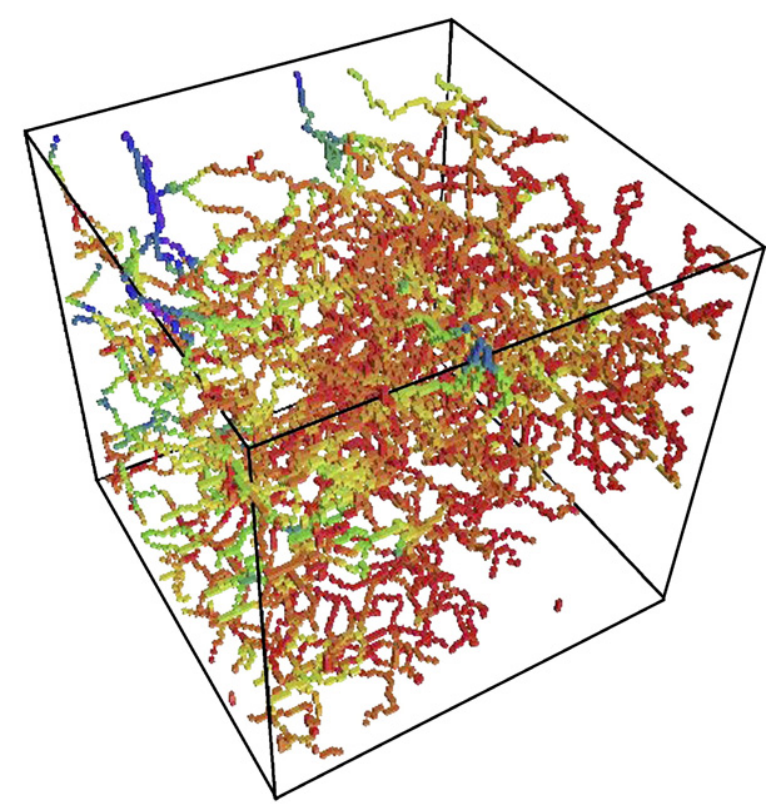

Fig. 9. A plot of the 3-D medial axis connecting pathways for the void space within the BLR-667 sediment sample (dimensions: $100 \times 100 \times 100$ voxels). Different voxel colors indicate the distance of the voxel to the closest grain voxel. The smallest distance is shown in red (narrow pores) and the largest in violet (wider pores). Intermediate values are indicated in colors along a rainbow scale. The softwares used to display the data included Inventor (http://oss.sgi. com/projects/inventor/)) and Geomview (http://www.geomview.org).

are given in Table 2. Values for the 3DMA-rock approach are roughly a factor of seven lower than values found using the correlation function. We believe the value determined from the actual area calculation is a more direct measurement and, hence, is the more reliable of the two.

The permeability is estimated by using a modified Kozeny-Carman equation (Brace, 1977; Berryman and Blair, 1987; Walsh and Brace, 1994). The relationship is

$k=\Phi^{2} /\left(b F s^{2}\right)$

where $\Phi$ is the porosity, $b$ is a geometric factor describing the pore structure, $F$ is the formation factor (a dimensionless constant representing the ratio of electrical resistivity of a rock containing void space filled with a fluid to the value for the fluid), and $s$ is the specific surface area of the material. We used a value of $b=2$ corresponding to the assumption of circular pore pathways and our measured CMT porosity values and specific surface area. The formation factor was assumed to be approximated by $F=1 / \Phi^{2}$ following the work of Blair et al. (1996). The calculated permeabilities are much higher than the values found by Blair et al. for typical 
sandstones reflecting the large difference in specific surface areas. Determination of grain size from the covariance function is more problematical. The data shown in Fig. 8 indicate that the grain size is approximately $100 \mu \mathrm{m}$, but this clearly does not adequately include the very small particles. We conclude that this approach provides qualitative information on the grain size but does not replace other size measuring approaches.

We have further processed segmented data to obtain medial axis information from the Lee-Kashyap-Chu algorithm (Lee et al., 1994) that is a part of the 3DMArock software. The medial axis consists of 26-connected paths of voxels (that are inherently two-dimensional) that preserve the original topology and geometry of the object. Medial axis determination is sensitive to noise in the image, and after some necessary modification to remove spurious paths, it represents connected fluid-flow pathways through the sediment (Fig. 9). More details about the medial axis algorithm employed can be found in Lindquist et al. (1996). The rainbow colors of the medial axis voxels in Fig. 9 depict the distance from the voxel to the closest rock voxel where red is the closest distance (narrow pores) and violet is the furthest (wider pores).

Medial axis analysis provides us with the ability to investigate tortuosity of the fluid pathways between the two opposite sides of a test sediment specimen. Fig. 10

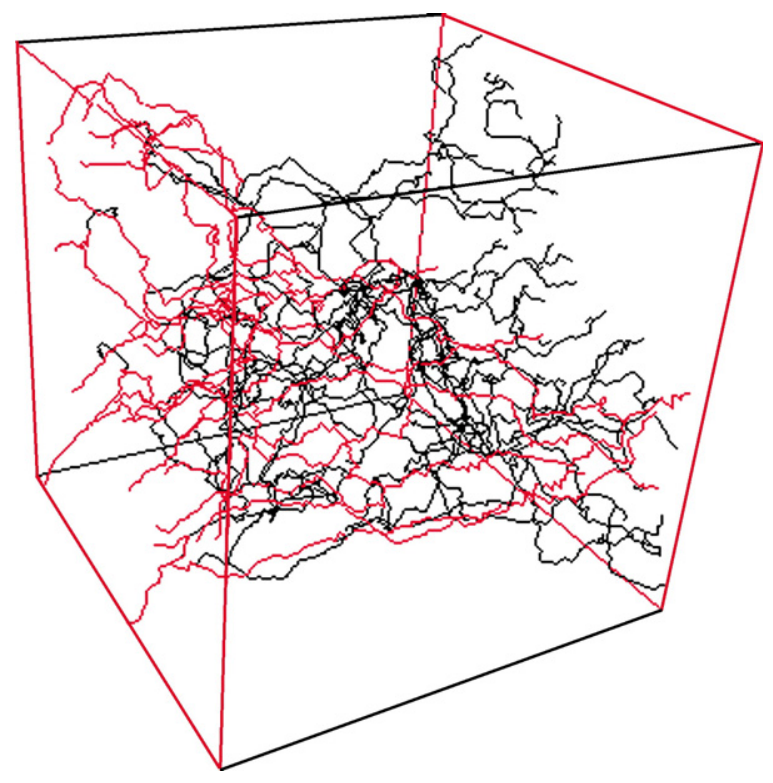

Fig. 10. An expanded Geomview plot of connecting pathways in a segment of the 3-D image shown in Fig. 9. The figure shows all pathways from one (user specified) side of the volume to the opposite one (in black). The shortest such pathways are shown in red. shows medial axis pathway nodes from one side of the sample to the opposite side. The shortest paths are shown in red. Tortuosity of all medial axis pathways from one side of the volume to another is measured as follows: all pairs of medial axis path endpoints $(i, j)$ are found, where $i$ and $j$ belong to the different volume sides. The algorithm finds the shortest path from $i$ to $j$ through the medial axis network. The (geometrical) tortuosity of the path is then obtained by dividing the length of this shortest path with the Euclidean distance of voxels $i$ and $j$. Average values found for the tortuosity from the medial axis analysis of the sediments are given in Table 2.

\section{Conclusions}

We evaluated the applicability of the CMT technique by carrying out an initial exploratory study of the microstructure of three sediment samples recovered from the Blake Ridge and Georges Bank. The results reported herein for the three grain sized sediment samples show the feasibility of non-destructive examination of the sediment samples. The extracted values for porosity and other parameters such as 3-D morphology, pore-space pathways, and permeability are also reported for the three samples. The CMT data derived results also show that changes in the measured parameters and visual examination of the 3-D tomographic data could be used to determine the physical relation between sediment grains and gas hydrate. For that, we plan to extend the laboratory investigations to host sediments containing tetrahydrofuran as a surrogate for methane hydrates to provide a more realistic evaluation of the interaction of fluids with sediment grains under controlled conditions of temperature and pressure. The methods developed will then be extended to study methane hydrate in sediments, which require high pressure sample handling for stabilization during measurements.

\section{Acknowledgements}

Research was supported in part by the US Department of Energy Contract No. DE-AC02-98CH10886 (KWJ and HF). Additional support was provided through the Laboratory Directed Research and Development (LDRD) program at Brookhaven National Laboratory to DM. The authors wish to thank the Ocean Drilling Program for providing the sediment sample upon which this study was based. We are grateful to W. B. Lindquist for the help with the application of the 3DMA software to characterization of the tomographic data. 


\section{References}

Berryman, J.G., Blair, S., 1986. Use of digital image analysis to estimate fluid permeability of porous materials: application of two-point correlation functions. Journal of Applied Physics 60, 1930-1938.

Berryman, J.G., Blair, S.C., 1987. Kozeny-Carman relations and image processing methods for estimating Darcy's constant. Journal of Applied Physics 62, 2221-2228.

Blair, S.C., Berge, P.A., Berryman, J.G., 1996. Using two-point correlation functions to characterize microgeometry and estimate permeabilities of sandstones and porous glass. Journal of Geophysical Research 101 (B9), 20359-20375.

Brace, W.F., 1977. Permeability from resistivity and pore shape. Journal of Geophysical Research 82, 3343-3349.

Clennell, M.B., Hovland, M., Booth, J.S., Henry, P., Winters, W.J., 1999. Formation of natural gas hydrates in marine sediments; 1 , conceptual model of gas hydrate growth conditioned by host sediment properties. Journal of Geophysical Research, B, Solid Earth and Planets 104 (10), 22,985-23,003.

Coles, M.E., Hazlett, R.D., Spanne, P., Soll, W.E., Muegge, E.L., Jones, K.W., 1998. Pore level imaging of fluid transport using synchrotron X-ray microtomography. Journal of Petroleum Science and Engineering 19, 55-63.

Collett, T.S., 2001. Natural-gas hydrates; resource of the twenty-first century? American Association of Petroleum Geologists (AAPG) Memoir 74, 85-108.

Collett, T.S., Dallimore, S.R., Anonymous, 2000. Identification and remediation of gas hydrate induced drilling and production hazards. Annual Meeting, Expanded Abstracts. American Association of Petroleum Geologists, vol. 30.

Dillon, W.P., Nealon, J.W., Taylor, M.H., Lee, M.W., Drury, R.M., Anton, C.H., 2001. Seafloor collapse and methane venting associated with gas hydrate on the Blake Ridge; causes and implications to seafloor stability and methane release. In: Paull, C.K., Dillon, W.P. (Eds.), Natural Gas Hydrates, Occurrence, Distribution, and Detection. Geophysical Monograph, vol. 124. American Geophysical Union, Washington, D.C., pp. 211-233.

Dowd, B.A., Andrews, A.B., Marr, R.B., Siddons, D.P., Jones, K.W., Peskin, A.M., 1999. Advances in X-ray computed microtomography at the NSLS. In: Huang, T.C., Barton, R., Buhrke, V.E., Gilfrich, J.V., Havrilla, G.J., Jenkins, R., Noyan, I.C., Predecki, P.K., Smith, D.K., Snyder, R.L. (Eds.), Presented at 47th Annual Denver X-Ray Conference, Colorado Springs, Colorado, August 3-7, 1998. Advances in X-Ray Analysis, vol. 42. Plenum Publishing Corp., New York, pp. 171-180.

Emery, K.O., Uchupi, E., 1965. Structure of Georges Bank. Marine Geology 3, 349-358.

Heezen, B.C., Hollister, C.D., Ruddiman, W.F., 1966. Shaping of the continental rise by deep geostrophic counter currents. Science 152 (3721), 502.

Freud, P.J., Trainer, M.N., Weiss, E.L., 1990. Particle measurement by linear system modeling and inversion of scattered light. Presented at Pittsburgh Conference 1990, Symposium on Powder Characterization and Particle Size Analysis, New York, March 5-9, 1990

Freud, P.J., Clark, A.H., Frock, H.N., 1993. Unified scatter technique for full-range particle size measurement. Presented at Pittsburgh Conference 1993, Atlanta, Georgia, March 8-12, 1993.

ISO Standard13320-1 Particle Size Analysis - Laser Diffraction Methods. Part 1.General Principles. International Organization for Standardization (ISO), 1, rue de Varembé, Case postale 56, CH1211 Geneva 20, Switzerland.
Jones, K.W., Feng, H., Lindquist, W.B., Adler, P.M., Thovert, J.F., Vekemans, B., Vincze, L., Szaloki, I., van Grieken, R., Adams, F., Riekel, C., 2003. Study of microtomography of porous materials using synchrotron computed microtomography. In: Mees, F., Swennen, R., VanGeet, M., Jacobs, P. (Eds.), Applications of XRay Computed Tomography in the Geosciences. Geological Society of London Special Publications, vol. 15. The Geological Society of London, pp. 39-49.

Kennett, J.P., Cannariato, K.G., Hendy, I.L., Behl, R.J., 2003. Methane Hydrates in Quaternary Climate Change - the Clathrate Gun Hypothesis. American Geophysical Union, Washington, D.C. 216 pp.

Kvenvolden, K.A., Lorenson, T.D., 2001. The global occurrence of natural gas hydrate. In: Paull, C.K., Dillon, W.P. (Eds.), Natural Gas Hydrates, Occurrence, Distribution, and Detection. Geophysical Monograph, vol. 124. American Geophysical Union, Washington, D.C., pp. 3-18.

Lee, T.C., Kashyap, R.L., Chu, C.N., 1994. Building skeleton models via $\{3-D\}$ medial surface/axis thinning algorithms. CVGIP: Graphical Models and Image Processing 56, 462-478.

Lindquist, W.B., Lee, S.M., Coker, D.A., Jones, K.W., Spanne, P., 1996. Medial axis analysis of void structure in three-dimensional tomographic images of porous media. Journal of Geophysical Research 101, 8297-8310.

Lorensen, W.E., Cline, H.E., 1987. Marching cubes: a high resolution 3-D surface reconstruction. In: Stone, M.C. (Ed.), Proceedings of the 14th Annual Conference on Computer Graphics and Interactive Techniques, vol. 21. Association for Computing Machinery (ACM), New York, pp. 163-169.

Mikami, J., Masuda, Y., Uchida, T., Satoh, T., Takeda, H., 2000. Dissociation of natural gas hydrates observed by X-ray CT scanner. In: Holder, G.D., Bishnoi, P.R. (Eds.), Gas Hydrates, Challenges for the Future. Annals of the New York Academy of Sciences, vol. 912. New York Academy of Sciences, New York, pp. 1011-1020.

Oh, Wonho, Lindquist, W.B., 1999. Image thresholding by indicator kriging. IEEE Transactions on Pattern Analysis and Machine Intelligence 21, 590-602.

Paull, C.K., Ussler III, W., Dillon, W.P., 2000a. Potential role of gas hydrate decomposition in generating submarine slope failures. Coastal Systems and Continental Margins. Natural Gas Hydrate in Oceanic and Permafrost Environments, vol. 5. Kluwer Academic Publishers, Dordrecht, pp. 149-156.

Paull, C.K., Matsumoto, R., Wallace, P.J., Black, N.R., Borowski, W.S., Collett, T.S., Damuth, J.E., Dickens, G.R., Egeberg, P.K., Goodman, K., Hesse, R.F., Hiroki, Y., Holbrook, W.S., Hoskins, H., Ladd, J., Lodolo, E., Lorenson, T.D., Musgrave, R.J., Naehr, T.H., Okada, H., Pierre, C., Ruppel, C.D., Satoh, M., Thiery, R., Watanabe, Y., Wehner, H., Winters, W.J., Wood, W.T., 2000b. Leg 164 overview. Proceedings of the Ocean Drilling Program, Scientific Results 164, $3-10$.

Sakai, A., 1999. Velocity analysis of vertical seismic profile (VSP) survey at JAPEX/JNOC/GSC Mallik 2L-38 gas hydrate research well, and related problems for estimating gas hydrate concentration. Bulletin - Geological Survey of Canada, Report 544, 323-340.

Sloan Jr., E.D., 1998. Clathrate Hydrates of Natural Gases. Marcel Dekker Inc., New York. 705 pp

Tomutsa, L., Freifeld, B., Kneafsey, T., Stern, L.A., 2002. X-ray computed tomography observation of methane hydrate dissociation. SPE 75533, SPE Gas Technology Symposium, Calgary, Alberta, Canada, April 30-May 2, 2002. Society of Petroleum Engineers.

Uchida, T., Dallimore, S., Mikami, J., 2000. Occurrences of natural gas hydrates beneath the permafrost zone in Mackenzie Delta visual 
and X-ray CT imagery. In: Holder, G.D., Bishnoi, P.R. (Eds.), Gas Hydrates, Challenges for the Future. Annals of the New York Academy of Sciences, vol. 912. New York Academy of Sciences, New York, pp. 1021-1033.

Walsh, J.B., Brace, W.F., 1994. The effect of pressure on porosity and the transport properties of rock. Journal of Geophysical Research 89, 9425-9431.

Winters, W.J., Dallimore, S.R., Collett, T.S., Katsube, T.J., Jenner, K.A., Cranston, R.E., Wright, J.F., Nixon, F.M., Uchida, T., 1999. Physical properties of sediments from the JAPEX/JNOC/GSC Mallik 2L-38 gas hydrate research well. In: Dallimore, S.R., Uchida, T., Collett, T.S. (Eds.), Scientific Results from JAPEX/ JNOC/GSC Mallik 2L-38 Gas Hydrate Research Well, Mackenzie Delta, Northwest Territories, Canada. Bulletin - Geological Survey of Canada, Report, vol. 544, pp. 95-100.

Winters, W.J., Paull, C.K., Matsumoto, R., Wallace, P.J., Black, N.R., Borowski, W.S., Collett, T.S., Damuth, J.E., Dickens, G.R., Egeberg, P.K., Goodman, K., Hesse, R.F., Hiroki, Y., Holbrook, W.S., Hoskins, H., Ladd, J., Lodolo, E., Lorenson, T.D., Musgrave, R.J., Naehr, T.H., Okada, H., Pierre, C., Ruppel, C.D., Satoh, M., Thiery, R., Watanabe, Y., Wehner, H., Wood, W.T., 2000a. Stress history and geotechnical properties of sediment from the Cape Fear Diapir, Blake Ridge Diapir, and Blake Ridge. Proceedings of the Ocean Drilling Program. Scientific Results, vol. 164, pp. 421-429. Winters, W.J., Paull, C.K., Matsumoto, R., Wallace, P.J., Black, N.R., Borowski, W.S., Collett, T.S., Damuth, J.E., Dickens, G.R., Egeberg, P.K., Goodman, K., Hesse, R.F., Hiroki, Y., Holbrook, W.S., Hoskins, H., Ladd, J., Lodolo, E., Lorenson, T.D., Musgrave, R.J., Naehr, T.H., Okada, H., Pierre, C., Ruppel, C.D., Satoh, M., Thiery, R., Watanabe, Y., Wehner, H., Wood, W.T., 2000b. Data report; effects of drying methods and temperatures on water content and porosity of sediment from the Blake Ridge. Proceedings of the Ocean Drilling Program, Scientific Results 164, 431-434.

Wright, J.F., Dallimore, S.R., Nixon, F.M., 1999. Influence of grain size and salinity on pressure-temperature thresholds for methane hydrate stability in JAPEX/JNOC/GSC Mallik 2L-38 gas hydrate research-well sediments. Bulletin - Geological Survey of Canada, Report 544, 229-240. 